\title{
Young adult-onset distal hereditary motor neuropathy
}

INSERM

\section{Source}

INSERM. (1999). Orphanet: an online rare disease and orphan drug data base. Young adult-onset distal hereditary motor neuropathy. ORPHA:314485

Young adult-onset distal hereditary motor neuropathy is a rare autosomal recessive distal hereditary motor neuropathy characterized by slowly prog ressive muscular weakness, hypotonia and atrophy of the lower limbs, more pronounced distally, leading to paralysis, and loss of tendon reflexes. Additional features may include pes cavus and mild dysphonia. The upper limbs are relatively spared. 